\title{
Satisfaction with oral anticoagulants in patients with atrial fibrillation
}

This article was published in the following Dove Press journal:

Patient Preference and Adherence

\section{Carmen Suárez Fernández,' Luis Castilla-Guerra, ${ }^{2}$ Jesus Cantero Hinojosa, ${ }^{3}$ Josep Maria Suriñach, ${ }^{4}$ Fernando Acosta de Bilbao, ${ }^{5}$ Juan José Tamarit,' José Luis Diaz Diaz,' Jose Luis Hernandez, ${ }^{8}$ Antonio Pose, ${ }^{9}$ Manuel Montero- Pérez-Barquero, ${ }^{10}$ Jaume Roquer, " Jaime Gállego, ${ }^{12}$ José Vivancos, ${ }^{13}$ Jose María Mostaza $^{14}$}

'Internal Medicine Service, Hospital Universitario de La Princesa, Madrid, ${ }^{2}$ Internal Medicine Department, Hospital Virgen Macarena, Seville, ${ }^{3}$ Internal Medicine Service, Hospital San Cecilio, Granada, ${ }^{4}$ Internal Medicine Service, Hospital Vall D Hebron, Barcelona, ${ }^{5}$ Internal Medicine Service, Complejo Hospitalario Universitario Insular Materno-Infantil, Las Palmas de Gran Canaria, ${ }^{6}$ Internal Medicine Service, Hospital General De Valencia, Valencia, ${ }^{7}$ Internal Medicine Service, Complejo Universitario Hospitalario de A Coruña, La Coruña, ${ }^{8}$ Internal Medicine Service, Hospital Marqués de Valdecilla, Universidad de Cantabria, Santander, 'Internal Medicine Service, Complejo Hospitalario Universitario de Santiago de Compostela, Santiago de Compostela, ${ }^{10}$ Internal Medicine Service, Instituto Maimónides de Investigación Biomédica de Córdoba (IMIBIC), Hospital Reina Sofía, Universidad de Córdoba, Córdoba, "Neurology Service, Hospital del Mar, Barcelona, ${ }^{12}$ Neurology Service, Complejo Hospitalario de Navarra, Pamplona, Navarra, ${ }^{13}$ Neurology Service, Hospital Universitario de La Princesa, Instituto de Investigación Sanitaria La Princesa, Madrid, ${ }^{14}$ Internal Medicine Service, Hospital Carlos III, Madrid, Spain

Correspondence: Carmen Suárez Fernández Internal Medicine Service, Hospital Universitario de La Princesa, Calle de Diego Leon, 62, 28006 Madrid, Spain Email csuarezf@salud.madrid.org
Background: Although, by itself, atrial fibrillation is associated with an impairment of quality of life antithrombotic therapy may play a role.

Objective: To evaluate the satisfaction with anticoagulant treatment in patients with nonvalvular atrial fibrillation who attended internal medicine departments in Spain.

Methods: Patients from two different cross-sectional studies were combined. To measure the satisfaction with anticoagulant treatment, the Anti-Clot-Treatment Scale (ACTS) questionnaire was completed by every patient. A multivariate analysis was performed to determine the variables associated with satisfaction of patients receiving oral anticoagulants.

Results: A total of 1,309 patients (mean age 78.5 \pm 8.4 years; $49.3 \%$ men; $\mathrm{CHA}_{2} \mathrm{DS}_{2}$ VASC 4.9 \pm 1.5 ; HAS-BLED 2.0 \pm 0.9 ) were included in the study, of whom 902 (68.9\%) were taking vitamin $\mathrm{K}$ antagonists (VKA) and 407 (31.1\%) direct oral anticoagulants (DOACs). Overall, satisfaction with oral anticoagulation was high (ACTS Burdens scale 49.69 \pm 9.45 ; ACTS Benefits scale 11.35 \pm 2.61 ). The perceived burdens with anticoagulant treatment were lower in men, as well as in patients with no dependency, normal renal function, who were not polymedicated, or who had moderate bleeding risk. Among patients taking VKA, those subjects with a lower number of International Normalized Ratio (INR) determinations in the last 6 months or with an optimal time in the therapeutic range exhibited a lower perceived burden. Patients taking DOACs (vs VKA) showed a lower perceived burden with anticoagulation. Benefits with anticoagulation were higher in men, younger patients, those with no dependency, or low bleeding risk. Perceived benefits were higher in patients taking DOACs (vs VKA).

Conclusion: Satisfaction with oral anticoagulation was high in patients with nonvalvular atrial fibrillation, who were attending internal medicine departments daily in Spain. Among patients taking VKA, those subjects with a lower number of INR determinations in the last 6 months or with an optimal time in the therapeutic range exhibited a lower perceived burden with anticoagulant therapy. Patients taking DOACs (vs VKA) showed lower perceived burdens and higher perceived benefits with anticoagulation.

Keywords: atrial fibrillation, benefit, burdens, direct oral anticoagulants, satisfaction, vitamin K antagonists

\section{Introduction}

Atrial fibrillation (AF) markedly increases the risk of stroke, mortality, and length of hospital stay. ${ }^{1}$ Importantly, stroke caused by AF has higher rates of death, disability, and recurrence than stroke of other etiologies. ${ }^{2,3}$

The great majority of patients with AF should be anticoagulated for the prevention of stroke. ${ }^{4}$ Although AF is associated with an impairment of quality of life by itself, antithrombotic therapy may play a role in this context. ${ }^{5}$ 
During the past decades vitamin $\mathrm{K}$ antagonists (VKA) have been the cornerstone for the prevention of thromboembolic complications in patients with AF. ${ }^{6}$ They are effective and safe but they have many disadvantages, such as the narrow therapeutic window, periodic coagulation monitoring or frequent changes in the dosage, that have limited their use in clinical practice and may have an impact on quality of life of patients. ${ }^{5-7}$

The introduction of direct oral anticoagulants (DOACs) in clinical practice has changed the patterns of anticoagulation nowadays. ${ }^{8}$ In fact, current European guidelines recommend the use of DOACs over VKA when oral anticoagulation is initiated and switching from VKA to DOACs in case of sub-optimal time in the therapeutic range. DOACs have some advantages over VKA that could impact positively on quality of life of anticoagulated patients. ${ }^{9}$

A high satisfaction with treatment is important, since it has been associated with higher rates of medication adherence and improved quality of life. ${ }^{5,10}$ Unfortunately, although quality of life and satisfaction with anticoagulant treatment should be considered as a target by themselves in the management of patients with AF, the information currently available about satisfaction with anticoagulant treatment in this population is clearly insufficient. ${ }^{11-16}$

The aim of this study was to evaluate the satisfaction with anticoagulant treatment in patients with nonvalvular $\mathrm{AF}$ in Spain. For this purpose, patients from two different databases (the ALADIN [Validación del cuestionario ACTS en pacientes con Fibrilación Auricular tratados con anticoagulantes orales en consultas de medicina interna y neurología de España] study and the ESPARTA [Estudio sobre el seguimiento en la práctica clínica de las recomendaciones sobre el tratamiento con anticoagulantes orales en pacientes con fibrilación auricular de edad avanzada] study) were combined. ${ }^{11,17}$

\section{Methods}

The ALADIN study aimed to validate the Anti-ClotTreatment Scale (ACTS) questionnaire in outpatients with nonvalvular AF treated with oral anticoagulants in internal medicine and neurology departments in Spain. ${ }^{11}$ The aim of the ESPARTA study was to evaluate the adherence to the recommendations in clinical practice, using the Therapeutic Positioning Report, about the treatment with oral anticoagulants in patients aged $\geq 75$ years old with nonvalvular $\mathrm{AF}$ attending internal medicine departments (hospitalized or outpatients) in Spain. ${ }^{17}$ In this study, in order to increase the homogeneity of the study population, only those patients who attended internal medicine departments were included
(472 patients from the ALADIN study and 837 patients from the ESPARTA study). Both studies were approved by the Clinical Research Ethics Committee of the University Hospital La Princesa of Madrid. All patients signed the written informed consent before inclusion.

In the ALADIN study, patients were recruited between September 2014 and March 2015 and in the ESPARTA study, patients were recruited from October 2015 to March 2016. In both cases, the studies involved a single visit that coincided with one of the patient's regular follow-up visits. In ALADIN and ESPARTA studies, to be included, patients should have received the same oral anticoagulant for at least 3 months. No specific diagnostic or therapeutic intervention was performed during the study. The data were collected from the medical history and physician interview and were entered in a case report form. Sociodemographic information (age, sex, level of dependency), comorbidities, estimated glomerular filtration rate (MDRD-4), treatments (type of oral anticoagulant, time in the therapeutic range and site of International Normalized Ratio (INR) determination in those patients taking VKA, concomitant drugs), as well as $\mathrm{CHADS}_{2}, \mathrm{CHA}_{2} \mathrm{DS}_{2}$-VASc, and HAS-BLED scores were recorded. ${ }^{9}$ Polymedication was defined as the regular consumption of $\geq 5$ tablets daily at the time of the visit. Physicians asked the patient or their relatives whether the patient had partial dependency (need help for at least one of the following activities: personal care, eating, getting dressed, or moving), total dependency (need help for all previously mentioned activities) or no dependency. Comorbidity was determined according to the Charlson Comorbidity Index. High comorbidity was defined as a score $\geq 3 .{ }^{18}$

All patients from both studies completed the ACTS questionnaire. The ACTS questionnaire is a patient-reported measure of satisfaction with anticoagulant treatment. It includes 12 items that assess the perceived burdens of anticoagulant treatment and three items that assess the perceived benefits of anticoagulant treatment. Patients are required to report their experiences with anticoagulant therapy during the past 4 weeks on a 5-point scale of intensity (from not at all - 1- to extremely -5-). The ACTS Burdens total score ranges from 12 to 60 (reverse-scored: higher score indicates less burden, and consequently, a higher satisfaction with anticoagulant treatment), and the ACTS Benefits total score ranges from 3 to 15 (direct-scored: higher score implies higher perceived benefit and secondarily, a higher satisfaction with anticoagulant treatment). ${ }^{19,20}$

\section{Statistical analysis}

For the descriptive analysis, quantitative variables were described with measures of central tendency and dispersion 
(mean and SD) and qualitative variables were described as absolute (n) and relative (\%) frequencies. To compare satisfaction among different subgroups of patients the MannWhitney $U$ test and the Kruskal-Wallis test were used, according to the number of groups being compared (two or more, respectively).

A logistic regression analysis was performed to identify those variables associated with satisfaction with oral anticoagulation regarding burdens and perceived benefits of anticoagulation. All variables with a $P$-value of less than 0.20 in the univariate analyses were included in the multivariate analyses.

Statistical significance was set at a $P$-value $<0.05$. The statistical analysis was performed using the SAS statistics package, version 9.4 .

\section{Results}

A total of 1,309 anticoagulated patients (mean age 78.5 \pm 8.4 years; $49.3 \%$ men; $\mathrm{CHA}_{2} \mathrm{DS}_{2}$-VASc $4.9 \pm 1.5$; HAS-BLED $2.0 \pm 0.9$ ) were included in the study (Table 1) of whom 902 (68.9\%) were taking VKA and 407 (31.1\%) DOACs.

With regard to perceived burdens with anticoagulation, overall, satisfaction with oral anticoagulation was high (49.69 \pm 9.45$)$. The perceived burdens with anticoagulant treatment were lower (higher satisfaction) in men (50.44 \pm 9.31 vs $48.95 \pm 9.54 ; P=0.01)$, as well as in patients with no dependency $(50.95 \pm 8.74$ vs 48.02 $\pm 9.94 / 46.53 \pm 11.14 ; P<0.001)$, normal renal function $(50.39 \pm 9.08$ vs $48.90 \pm 9.82 ; P=0.008)$, or not polymedicated

Table I Clinical characteristics of the study population

\begin{tabular}{|c|c|}
\hline Variable & $\begin{array}{l}\text { Total } \\
(n=1,309)\end{array}$ \\
\hline Age (years) & $78.5 \pm 8.4$ \\
\hline Sex male (\%) & 49.3 \\
\hline \multicolumn{2}{|l|}{ Level of dependency (\%) } \\
\hline No dependency & 59.9 \\
\hline Partial dependency & 34.4 \\
\hline Total dependency & 5.7 \\
\hline Permanent atrial fibrillation (\%) & 82.9 \\
\hline Hypertension (\%) & 86.7 \\
\hline Heart failure (\%) & 58.7 \\
\hline Glomerular filtration $\leq 60 \mathrm{~mL} / \mathrm{min} / \mathrm{l} .73 \mathrm{~m}^{2}(\%)$ & 57.2 \\
\hline Diabetes $(\%)$ & 40.4 \\
\hline Prior stroke (\%) & 19.4 \\
\hline Mean $\mathrm{CHADS}_{2}$ score & $3.2 \pm 1.2$ \\
\hline Mean $\mathrm{CHA}_{2} \mathrm{DS}_{2}$-VASc score & $4.9 \pm 1.5$ \\
\hline Mean HAS-BLED score & $2.0 \pm 0.9$ \\
\hline Charlson Comorbidity Index & $2.3 \pm 1.8$ \\
\hline Polymedicated ( $\geq 5$ tablets, $\%$ ) & 90.7 \\
\hline TRT $\leq 50 \%$ (only in VKA patients, \%) & 50.6 \\
\hline
\end{tabular}

Abbreviations: TRT, time in the therapeutic range; VKA, vitamin $\mathrm{K}$ antagonists.
(51.41 \pm 8.54 vs $49.53 \pm 9.50 ; P=0.04)$. In addition, in those patients with a moderate bleeding risk, burdens with oral anticoagulation were lower. Among patients taking VKA, those subjects with a lower number of INR determinations in the last 6 months $(50.36 \pm 7.85$ vs $47.35 \pm 10.58$ vs $46.24 \pm 10.77 ; P=0.01)$ or with an optimal time in the therapeutic range $(49.02 \pm 9.24$ vs $47.07 \pm 10.35 ; P=0.024)$ exhibited a lower perceived burden with anticoagulant therapy. Patients taking DOACs (vs VKA) showed a lower perceived burden with anticoagulation, regardless of age, sex, level of dependency, renal function, number of pills, thromboembolic or bleeding risk, comorbidities, or duration of treatment with anticoagulants (Table 2).

With regard to perceived benefits with anticoagulant treatment, overall, the perceived benefits were high (11.35 \pm 2.61 ). Perceived benefits with anticoagulation were higher in men (11.49 \pm 2.57 vs $11.21 \pm 2.64 ; P=0.03)$, younger patients, or with no dependency (11.62 \pm 2.63 vs $11.00 \pm 2.53 / 10.57 \pm 2.56$; $P<0.001)$. In addition, in those patients with a low bleeding risk $(11.70 \pm 2.31$ vs $11.46 \pm 2.65$ vs $11.13 \pm 2.48 ; P=0.02)$ the perceived benefits with oral anticoagulation were higher. Among patients taking VKA, those subjects with a low or high number of INR determinations in the last 6 months (11.59 \pm 2.27 vs $10.86 \pm 2.61$ vs $11.95 \pm 2.92 ; P<0.001)$ exhibited a higher perceived benefit with anticoagulant therapy. Perceived benefits were higher in patients taking DOACs (vs VKA), regardless of age, sex, level of dependency, renal function, number of pills, thromboembolic or bleeding risk, comorbidities, or duration of treatment with anticoagulants (Table 3).

In the multivariate analysis, age (elderly), no dependency, the use of DOACs (vs VKA), and a higher glomerular filtration rate were associated with less perceived burden with anticoagulant treatment. In addition, a lower number of INR determinations and the site of INR determination (other than hematology department) were associated with a lower perceived burden with VKA. On the other hand, no dependency, low number of comorbidities, and the use of DOACs (vs VKA) were associated with higher perceived benefits with anticoagulant treatment. Similarly, the site of INR determination (other than hematology department) was associated with higher perceived benefits. Normal renal function was associated with higher perceived benefits with treatment with DOACs (Table 4).

\section{Discussion}

Our study suggests that satisfaction with oral anticoagulation may be high in AF patients who attended internal medicine departments daily. Since the majority of the studies that have 
Table 2 ACTS Burdens scale according to different clinical characteristics and the type of oral anticoagulant

\begin{tabular}{|c|c|c|c|c|c|}
\hline & Total $(n=I, 309)$ & $P$-value & VKA $(n=902)$ & DOACs $(n=407)$ & $P$-value \\
\hline Overall & $49.69 \pm 9.45$ & - & $48.12 \pm 9.79$ & $53.15 \pm 7.59$ & $<0.001$ \\
\hline \multicolumn{6}{|l|}{ Sex } \\
\hline Men & $50.44 \pm 9.31$ & 0.001 & $48.67 \pm 9.98$ & $54.14 \pm 6.29$ & $<0.001$ \\
\hline Women & $48.95 \pm 9.54$ & & $47.60 \pm 9.59$ & $52.12 \pm 8.65$ & $<0.001$ \\
\hline \multicolumn{6}{|l|}{ Age } \\
\hline 18-65 years & $46.70 \pm 9.49$ & & $44.55 \pm 9.95$ & $52.86 \pm 4.18$ & 0.005 \\
\hline $66-75$ years & $48.3 I \pm 9.94$ & NS* & $46.68 \pm \mid 0.31$ & $51.57 \pm 8.36$ & 0.01 \\
\hline $76-85$ years & $49.97 \pm 9.28$ & & $48.07 \pm 9.61$ & $53.74 \pm 7.24$ & $<0.001$ \\
\hline$\geq 86$ years & $49.7 I \pm 9.50$ & & $48.75 \pm 9.86$ & $52.49 \pm 7.78$ & 0.001 \\
\hline \multicolumn{6}{|l|}{ Level of dependency } \\
\hline No dependency & $50.95 \pm 8.74$ & & $49.25 \pm 9.25$ & $54.59 \pm 6.13$ & $<0.001$ \\
\hline Partial dependency & $48.02 \pm 9.94$ & $<0.00 I^{*}$ & $47.01 \pm 10.09$ & $50.44 \pm 9.14$ & 0.01 \\
\hline Total dependency & $46.53 \pm 11.14$ & & $43.10 \pm 10.98$ & $53.40 \pm 7.95$ & $<0.001$ \\
\hline \multicolumn{6}{|l|}{ Glomerular filtration } \\
\hline$\leq 60 \mathrm{~mL} / \mathrm{min} / \mathrm{l} .73 \mathrm{~m}^{2}$ & $48.90 \pm 9.82$ & 0.008 & $47.45 \pm 10.19$ & $52.47 \pm 7.79$ & $<0.001$ \\
\hline$>60 \mathrm{~mL} / \mathrm{min} / \mathrm{l} .73 \mathrm{~m}^{2}$ & $50.39 \pm 9.08$ & & $48.63 \pm 9.34$ & $53.86 \pm 7.43$ & $<0.001$ \\
\hline Site of INR determination & (only in VKA patients) & & & & \\
\hline Self-monitoring & $49.80 \pm 8.96$ & & $49.80 \pm 8.96$ & & \\
\hline Primary care center & $49.38 \pm 8.99$ & $<0.001 *$ & $49.38 \pm 8.99$ & - & - \\
\hline Hematology department & $43.83 \pm 10.94$ & & $43.83 \pm 10.94$ & & \\
\hline Hospital (other than hematology department) & $53.81 \pm 5.86$ & & $53.81 \pm 5.86$ & & \\
\hline Number of INR determinations in the last 6 months & (only in VKA patients) & & & & \\
\hline $0-5$ & $50.36 \pm 7.85$ & & $50.36 \pm 7.85$ & & \\
\hline $6-10$ & $47.35 \pm 10.58$ & $0.01 *$ & $47.35 \pm 10.58$ & - & - \\
\hline$>10$ & $46.24 \pm 10.77$ & & $46.24 \pm 10.77$ & & \\
\hline \multicolumn{6}{|l|}{ Number of pills } \\
\hline $0-5$ & $51.09 \pm 9.30$ & & $48.97 \pm 9.85$ & $55.09 \pm 6.56$ & $<0.001$ \\
\hline $6-10$ & $50.24 \pm 9.01$ & $0.01 *$ & $48.78 \pm 9.40$ & $53.4 I \pm 7.16$ & $<0.001$ \\
\hline $11-15$ & $48.79 \pm 9.98$ & & $47.17 \pm 10.39$ & $52.66 \pm 7.66$ & $<0.001$ \\
\hline$\geq 16$ & $49.12 \pm 9.25$ & & $47.94 \pm 9.13$ & $51.77 \pm 9.03$ & NS \\
\hline \multicolumn{6}{|l|}{ Polymedication } \\
\hline$<5$ tablets & $5 I .4 I \pm 8.54$ & 0.04 & $49.37 \pm 9.01$ & $54.50 \pm 6.74$ & 0.002 \\
\hline$\geq 5$ tablets & $49.53 \pm 9.50$ & & $48.03 \pm 9.83$ & $52.99 \pm 7.67$ & $<0.001$ \\
\hline \multicolumn{6}{|l|}{ Thromboembolic risk } \\
\hline $\mathrm{CHA}_{2} \mathrm{DS}_{2}-\mathrm{VASc}=0$ & $54.50 \pm 2.12$ & & - & $54.50 \pm 2.12$ & - \\
\hline $\mathrm{CHA}_{2} \mathrm{DS}_{2}-\mathrm{VASC}=\mathrm{I}$ & $48.00 \pm 6.23$ & NS* & $48.00 \pm 6.23$ & - & - \\
\hline $\mathrm{CHA}_{2} \mathrm{DS}_{2}-\mathrm{VASC} \geq 2$ & $49.68 \pm 9.50$ & & $48.09 \pm 9.82$ & $53.20 \pm 7.65$ & $<0.001$ \\
\hline \multicolumn{6}{|l|}{ Bleeding risk } \\
\hline HAS-BLED =0 & $47.30 \pm 7.85$ & & $44.00 \pm 8.46$ & $52.25 \pm 3.30$ & NS \\
\hline HAS-BLED $=I-2$ & $49.89 \pm 9.66$ & $0.0 I^{*}$ & $48.06 \pm 10.16$ & $53.27 \pm 7.60$ & $<0.001$ \\
\hline HAS-BLED $\geq 3$ & $48.72 \pm 9.40$ & & $47.72 \pm 9.58$ & $51.94 \pm 8.04$ & 0.001 \\
\hline \multicolumn{6}{|l|}{ Comorbidity } \\
\hline Absence & $50.9 \pm 9.3$ & & $49.7 \pm 9.6$ & $53.5 \pm 7.9$ & $<0.001$ \\
\hline Low & $49.7 \pm 9.9$ & $0.001 *$ & $47.8 \pm 10.1$ & $54.5 \pm 7.4$ & $<0.001$ \\
\hline High & $49.0 \pm 9.4$ & & $47.4 \pm 9.8$ & $52.4 \pm 7.6$ & $<0.001$ \\
\hline TRT & (only in VKA patients) & & & & \\
\hline$\leq 50 \%$ & $47.07 \pm 10.35$ & 0.024 & $47.07 \pm 10.35$ & - & - \\
\hline$>50 \%$ & $49.02 \pm 9.24$ & & $49.02 \pm 9.24$ & & \\
\hline \multicolumn{6}{|l|}{ Duration of treatment with anticoagulants (months) } \\
\hline $0-24$ & $50.74 \pm 9.12$ & & $47.36 \pm 10.08$ & $53.13 \pm 7.54$ & $<0.001$ \\
\hline $25-48$ & $50.4 I \pm 8.75$ & $<0.001 *$ & $49.32 \pm 8.87$ & $53.39 \pm 7.73$ & 0.003 \\
\hline $48-96$ & $48.17 \pm 9.49$ & & $47.61 \pm 9.59$ & $54.4 I \pm 5.24$ & 0.001 \\
\hline$>96$ & $48.26 \pm 10.30$ & & $48.33 \pm 10.24$ & $44.00 \pm 14.45$ & NS \\
\hline
\end{tabular}

Notes: $* P$ for trend. Data presented as mean $\pm S D$ unless otherwise indicated.

Abbreviations: ACTS, Anti-Clot-Treatment Scale; VKA, vitamin K antagonists; DOACs, direct oral anticoagulants; NS, not significant; INR, International Normalized Ratio; TRT, time in the therapeutic range. 
Table 3 ACTS Benefits scale according to different clinical characteristics and the type of oral anticoagulant

\begin{tabular}{|c|c|c|c|c|c|}
\hline & Total $(n=I, 309)$ & $P$-value & VKA $(n=902)$ & DOACs $(n=407)$ & $P$-value \\
\hline Overall & $11.35 \pm 2.61$ & - & $11.06 \pm 2.58$ & $11.99 \pm 2.56$ & $<0.001$ \\
\hline \multicolumn{6}{|l|}{ Sex } \\
\hline Men & $1 \mathrm{I} .49 \pm 2.57$ & 0.03 & $11.17 \pm 2.57$ & $12.17 \pm 2.45$ & $<0.001$ \\
\hline Women & $11.21 \pm 2.64$ & & $10.96 \pm 2.59$ & $11.81 \pm 2.67$ & 0.001 \\
\hline \multicolumn{6}{|l|}{ Age } \\
\hline 18-65 years & $11.93 \pm 2.35$ & & $11.70 \pm 2.45$ & $12.57 \pm 2.07$ & NS \\
\hline $66-75$ years & $11.70 \pm 2.29$ & $0.0 I^{*}$ & II. $.26 \pm 2.44$ & $12.59 \pm 1.62$ & 0.003 \\
\hline $76-85$ years & $11.43 \pm 2.60$ & & $11.16 \pm 2.59$ & $11.98 \pm 2.54$ & 0.001 \\
\hline$\geq 86$ years & $11.03 \pm 2.70$ & & $10.79 \pm 2.60$ & $11.73 \pm 2.87$ & 0.001 \\
\hline \multicolumn{6}{|l|}{ Level of dependency } \\
\hline No dependency & $11.62 \pm 2.63$ & & $11.36 \pm 2.56$ & $12.17 \pm 2.69$ & 0.001 \\
\hline Partial dependency & $11.00 \pm 2.53$ & $<0.00 I^{*}$ & $10.73 \pm 2.56$ & $11.65 \pm 2.36$ & $<0.001$ \\
\hline Total dependency & $10.57 \pm 2.56$ & & $9.98 \pm 2.42$ & $11.76 \pm 2.47$ & 0.03 \\
\hline \multicolumn{6}{|l|}{ Glomerular filtration } \\
\hline$\leq 60 \mathrm{~mL} / \mathrm{min} / 1.73 \mathrm{~m}^{2}$ & $11.28 \pm 2.59$ & NS & $11.04 \pm 2.55$ & $11.88 \pm 2.59$ & $<0.001$ \\
\hline$>60 \mathrm{~mL} / \mathrm{min} / \mathrm{I} .73 \mathrm{~m}^{2}$ & $|1.50 \pm 2.5|$ & & $11.19 \pm 2.46$ & $12.12 \pm 2.49$ & $<0.001$ \\
\hline Site of INR determination & (only in VKA patients) & & & & \\
\hline Self-monitoring & $12.20 \pm 3.83$ & & $12.20 \pm 3.83$ & & \\
\hline Primary care center & $11.20 \pm 2.52$ & $0.001 *$ & $11.20 \pm 2.52$ & - & - \\
\hline Hematology department & $10.57 \pm 2.66$ & & $10.57 \pm 2.66$ & & \\
\hline Hospital (other than hematology department) & $12.27 \pm 2.55$ & & $12.27 \pm 2.55$ & & \\
\hline Number of INR determinations in the last 6 months & (only in VKA patients) & & & & \\
\hline $0-5$ & $11.59 \pm 2.27$ & & $11.59 \pm 2.27$ & & \\
\hline $6-10$ & $10.86 \pm 2.61$ & $<0.00 I^{*}$ & $10.86 \pm 2.61$ & - & - \\
\hline$>10$ & $11.95 \pm 2.92$ & & $11.95 \pm 2.92$ & & \\
\hline \multicolumn{6}{|l|}{ Number of pills } \\
\hline $0-5$ & $11.18 \pm 3.00$ & & $10.80 \pm 3.09$ & $11.91 \pm 2.70$ & 0.02 \\
\hline $6-10$ & $11.40 \pm 2.68$ & NS* & $11.10 \pm 2.60$ & $12.05 \pm 2.74$ & $<0.001$ \\
\hline $11-15$ & $11.36 \pm 2.47$ & & $11.12 \pm 2.42$ & $\mid 1.94 \pm 2.51$ & 0.001 \\
\hline$\geq 16$ & $11.31 \pm 2.40$ & & $11.04 \pm 2.47$ & $11.89 \pm 2.15$ & 0.02 \\
\hline \multicolumn{6}{|l|}{ Polymedication } \\
\hline$<5$ tablets & $11.20 \pm 3.05$ & NS & $10.81 \pm 3.10$ & $11.79 \pm 2.89$ & NS \\
\hline$\geq 5$ tablets & $11.36 \pm 2.57$ & & $11.08 \pm 2.53$ & $12.00 \pm 2.53$ & $<0.001$ \\
\hline \multicolumn{6}{|l|}{ Thromboembolic risk } \\
\hline $\mathrm{CHA}_{2} \mathrm{DS}_{2}-\mathrm{VASc}=0$ & $13.50 \pm 2.12$ & & - & $13.50 \pm 2.12$ & - \\
\hline $\mathrm{CHA}_{2} \mathrm{DS}_{2}-\mathrm{VASc}=\mathrm{I}$ & $10.67 \pm 1.75$ & NS* & $10.67 \pm 1.75$ & - & - \\
\hline $\mathrm{CHA}_{2} \mathrm{DS}_{2}-\mathrm{VASc} \geq 2$ & $|1.35 \pm 2.6|$ & & $11.06 \pm 2.59$ & $12.00 \pm 2.55$ & $<0.001$ \\
\hline \multicolumn{6}{|l|}{ Bleeding risk } \\
\hline HAS-BLED $=0$ & $|1.70 \pm 2.3|$ & & $11.50 \pm 2.43$ & $12.00 \pm 2.45$ & NS \\
\hline HAS-BLED $=I-2$ & $11.46 \pm 2.65$ & $0.02 *$ & $11.19 \pm 2.61$ & $11.95 \pm 2.64$ & $<0.001$ \\
\hline HAS-BLED $\geq 3$ & $11.13 \pm 2.48$ & & $10.88 \pm 2.46$ & $11.96 \pm 2.34$ & 0.001 \\
\hline \multicolumn{6}{|l|}{ Comorbidity } \\
\hline Absence & $11.4 \pm 2.8$ & & $11.2 \pm 2.7$ & $11.9 \pm 2.9$ & 0.004 \\
\hline Low & $11.5 \pm 2.7$ & $0.02 *$ & $11.2 \pm 2.7$ & $12.3 \pm 2.8$ & $<0.001$ \\
\hline High & $11.2 \pm 2.4$ & & $10.9 \pm 2.4$ & $11.9 \pm 2.3$ & $<0.00$ I \\
\hline TRT & (only in VKA patients) & & & & \\
\hline$\leq 50 \%$ & $|0.90 \pm 2.5|$ & NS & $|0.90 \pm 2.5|$ & - & - \\
\hline$>50 \%$ & $11.13 \pm 2.68$ & & $11.13 \pm 2.68$ & & \\
\hline \multicolumn{6}{|l|}{ Duration of treatment with anticoagulants (months) } \\
\hline $0-24$ & $1 \mathrm{I} .44 \pm 2.72$ & & $10.86 \pm 2.72$ & $11.86 \pm 2.64$ & $<0.001$ \\
\hline $25-48$ & $11.65 \pm 2.54$ & $0.001 *$ & II. $.48 \pm 2.57$ & $|2.14 \pm 2.4|$ & NS \\
\hline $48-96$ & $11.05 \pm 2.63$ & & $10.89 \pm 2.63$ & $12.82 \pm 1.84$ & $<0.001$ \\
\hline$>96$ & $11.06 \pm 2.39$ & & $11.03 \pm 2.38$ & $13.25 \pm 2.36$ & NS \\
\hline
\end{tabular}

Notes: *P for trend. Data presented as mean \pm SD unless otherwise indicated.

Abbreviations: ACTS, Anti-Clot-Treatment Scale; VKA, vitamin K antagonists; DOACs, direct oral anticoagulants; NS, not significant; INR, International Normalized Ratio; TRT, time in the therapeutic range. 
Table 4 Variables associated with satisfaction of patients with oral anticoagulation

\begin{tabular}{|c|c|c|c|}
\hline & $P$-value & Beta & $95 \% \mathrm{Cl}$ \\
\hline \multicolumn{4}{|l|}{ ACTS Burdens scale } \\
\hline \multicolumn{4}{|l|}{ Overall } \\
\hline Age & 0.0005 & 1.674 & $0.733-2.614$ \\
\hline Dependency & $<0.0001$ & -3.625 & -4.664 to -2.587 \\
\hline Type of oral anticoagulant & $<0.0001$ & 5.678 & $4.437-6.919$ \\
\hline Glomerular filtration rate & 0.013 & $1.49 \mid$ & $0.315-2.667$ \\
\hline \multicolumn{4}{|l|}{ VKA } \\
\hline Age & 0.0021 & 2.131 & $0.778-3.484$ \\
\hline Dependency & $<0.0001$ & -4.893 & -6.354 to -3.431 \\
\hline Number of INR controls & 0.0039 & -2.248 & -3.77 to -0.725 \\
\hline Site of INR determination & $<0.0001$ & -4.118 & -5.632 to -2.604 \\
\hline \multicolumn{4}{|l|}{ DOACs } \\
\hline Dependency & 0.0014 & -2.263 & -3.64 to -0.885 \\
\hline \multicolumn{4}{|l|}{ ACTS Benefits scale } \\
\hline \multicolumn{4}{|l|}{ Overall } \\
\hline Dependency & 0.0003 & -0.501 & -0.773 to -0.229 \\
\hline Type of oral anticoagulant & $<0.0001$ & 0.957 & $0.628-1.287$ \\
\hline Comorbidity & 0.0008 & -0.100 & -0.158 to -0.041 \\
\hline \multicolumn{4}{|l|}{ VKA } \\
\hline Dependency & 0.0003 & -0.663 & -1.021 to -0.306 \\
\hline Site of INR determination & 0.0024 & -0.592 & -0.974 to -0.211 \\
\hline Comorbidity & 0.0440 & -0.084 & -0.165 to -0.002 \\
\hline \multicolumn{4}{|l|}{ DOACs } \\
\hline Serum creatinine & 0.0146 & -0.736 & -1.325 to -0.146 \\
\hline
\end{tabular}

Abbreviations: ACTS, Anti-Clot-Treatment Scale; VKA, vitamin K antagonists; INR, International Normalized Ratio; DOACs, direct oral anticoagulants.

analyzed patients with AF have focused on patients visiting cardiologists or general practitioners, ${ }^{21,22}$ the information provided in this study is of great interest, considering the high number of AF patients who are currently attending internal medicine departments.

In the last years, a number of studies have focused on analyzing the impact of anticoagulant therapy on quality of life of patients, using the ACTS questionnaire. ${ }^{11-16}$ The ACTS questionnaire has been specifically validated to assess satisfaction with anticoagulant therapy in patients with AF. It has been shown that ACTS questionnaire is reliable, valid, and feasible and requires only approximately 9 minutes to complete. ${ }^{18}$ Since satisfaction with treatment is important to assure good medication adherence in chronic conditions, satisfaction with anticoagulant therapy should routinely be determined as part of the comprehensive approach regarding patients with $\mathrm{AF} .^{5}$

In our study, perceived benefits were greater in younger patients, likely due to a higher perception of the need for stroke prevention in this population. In addition, perceived burdens were lower and perceived benefits higher in patients with no dependency, particularly with DOACs. In contrast to VKA, DOACs do not require periodic monitoring of anticoagulant activity or frequent changes in the dosage. ${ }^{7}$ In this context, due to advantages of DOACs over VKA, ${ }^{7}$ the use of DOACs could support an added value in the treatment of younger AF patients or those with no dependency who require anticoagulant therapy. The perceived burdens with anticoagulant treatment were lower (higher satisfaction) and the perceived benefits were higher in men. Available data suggest that women exhibit a worse quality of life and a worse health perception than men not only in AF, but also in several chronic clinical conditions. ${ }^{23}$

Perceived benefits were lower in patients with high risk of bleeding. This is of concern, since this may have an impact on the persistence and under-treatment of patients at high risk of bleeding, as these patients usually have a high thromboembolic risk. On the other hand, the perception of physicians about the thromboembolic and bleeding risk of their patients could be relevant regarding the choice of oral anticoagulant. Thus, it has been reported that the presence of a high thrombotic or hemorrhagic risk leads to choosing DOACs over VKA in patients with nonvalvular $\mathrm{AF}$, whereas renal failure, cognitive impairment, adequate control with dicoumarins, and a low bleeding risk predispose to selecting VKA. ${ }^{24}$

The influence of the duration of time with anticoagulant therapy on satisfaction was also analyzed. In our study, perceived burdens with anticoagulant therapy were lower and perceived benefits higher when anticoagulation was started within 48 months compared with longer periods of treatment. By contrast, a cross-sectional study showed that patients diagnosed with AF and with less than 1 year of anticoagulant use presented a worse health-related quality of life evaluation. ${ }^{25}$ This means that satisfaction with anticoagulant treatment may vary during the follow-up. As a result, it is not enough to determine satisfaction with anticoagulant treatment at the time of starting therapy, but also periodically during the follow-up.

Among patients taking VKA, those subjects with a lower number of INR determinations in the last 6 months or with an optimal time in the therapeutic range exhibited a lower perceived burden with anticoagulant therapy. Assuring good anticoagulation control is not only important for reducing the need of INR determinations, or improving satisfaction with treatment but more importantly, poor VKA control has been associated with higher risks of stroke, major bleeding, and all-cause mortality. ${ }^{26}$ Unfortunately, poor INR control is very common in clinical practice, since up to $40 \%-50 \%$ of patients taking VKA do not achieve an adequate time in the therapeutic range. ${ }^{21,22}$ 
On the other hand, the site of the INR determination (other than hematology department) was associated with lower perceived burdens and higher perceived benefits with anticoagulant treatment. Although it is evident that patients who attend the hematology department and receive anticoagulation therapy are more complex, and achieving an optimal time in the therapeutic range is more difficult in this population, making INR control in the primary care center is more comfortable for the patients (and results in higher patient satisfaction) than going to the hematology department. In fact, in Spain the majority of anticoagulated patients with VKA are attended to by general practitioners. ${ }^{21}$

One of the most relevant findings in our study was that patients taking DOACs (vs VKA) showed lower perceived burdens and higher perceived benefits with anticoagulation, regardless of many clinical variables, including age, sex, level of dependency, renal function, number of pills, thromboembolic or bleeding risk, comorbidities, or duration of treatment with anticoagulants. In addition, this was confirmed in the multivariate analysis. In the last years, a number of studies have shown that in general, satisfaction with anticoagulant therapy is superior with DOACs when compared with VKA. In the XANTUS-ACTS sub-study, switching from VKA to rivaroxaban was associated with significant improvements in ACTS burden and benefit scores. ${ }^{12}$ This also occurred in a French observational study. ${ }^{13}$ In addition, it has been reported that DOACs have an improved psychological impact compared with warfarin in elderly patients (less depression or anxiety). ${ }^{15}$ This is not surprising, since patients report having more limitations and having greater feelings of burden on warfarin than with DOACs. ${ }^{16}$

With regard to the limitations of the study, although this study was performed after the combination of two different databases, it should be considered that the methodology of both studies was very similar, and that all patients included attended internal medicine departments, assuring a good homogeneity among patients. Since this study was performed in nonvalvular AF patients attending internal medicine departments in Spain, the conclusions of this study can only be extended to patients with a similar clinical profile and health care system.

In conclusion, satisfaction with oral anticoagulation was high in patients with nonvalvular AF attending internal medicine departments daily in Spain. Among patients taking VKA, those subjects with a lower number of INR determinations in the last 6 months or with an optimal time in the therapeutic range exhibited a lower perceived burden with anticoagulant therapy. Patients taking DOACs (vs VKA) showed lower burdens and higher perceived benefits with anticoagulation.

\section{Acknowledgment}

We would like to acknowledge ALADIN and ESPARTA studies' investigators (Supplementary material). This study was funded by Bayer Hispania.

Writing and editorial assistance was provided by Content Ed Net Madrid with financial support from Bayer Hispania.

\section{Disclosure}

The authors report no conflicts of interest in this work.

\section{References}

1. Saad M, Elgendy IY, Mentias A, et al. Incidence, predictors, and outcomes of early atrial arrhythmias after lung transplant: a systematic review and meta-analysis. JACC Clin Electrophysiol. 2017;3(7):718-726.

2. Ceornodolea AD, Bal R, Severens JL. Epidemiology and management of atrial fibrillation and stroke: review of data from four European countries. Stroke Res Treat. 2017;2017:8593207.

3. Masjuán J, Álvarez-Sabín J, Blanco M, de Felipe A, Gil-Núñez A, Gállego-Culleré J, Vivancos J. Manejo actual del tratamiento antitrombótico en pacientes con fibrilación auricular no valvular y antecedentes de ictus o ataque isquémico transitorio. [Current management of antithrombotic treatment in patients with non valvular atrial fibrillation and prior history of stroke or transient ischemic attack]. Rev Neurol. 2014;59(1):25-36. Spanish.

4. Barrios V, Escobar C, Calderón A, Rodríguez Roca GC, Llisterri JL, Polo García J. Use of antithrombotic therapy according to CHA2DS2VASc score in patients with atrial fibrillation in primary care. Rev Esp Cardiol (Engl Ed). 2014;67(2):150-151.

5. Ynsaurriaga FA, Peinado RP, Ormaetxe Merodio JM. Atrial fibrillation and quality of life related to disease and treatment: focus on anticoagulation. Future Cardiol. 2014;10(3):381-393.

6. Hart RG, Pearce LA, Aguilar MI. Meta-analysis: antithrombotic therapy to prevent stroke in patients who have nonvalvular atrial fibrillation. Ann Intern Med. 2007;146(12):857-867.

7. Barrios V, Escobar C, Lobos JM, Polo J, Vargas D. Use of nonvitamin $\mathrm{K}$ antagonist oral anticoagulants in Primary Care: ACTUA study. Semergen. 2017;43(7):477-485.

8. Marzec LN, Wang J, Shah ND, et al. Influence of direct oral anticoagulants on rates of oral anticoagulation for atrial fibrillation. J Am Coll Cardiol. 2017;69(20):2475-2484.

9. Kirchhof P, Benussi S, Kotecha D, et al. 2016 ESC Guidelines for the management of atrial fibrillation developed in collaboration with EACTS. Eur Heart J. 2016;37(38):2893-2962.

10. Wang Y, Kong MC, Lee LH, Ng HJ, Ko Y. Knowledge, satisfaction, and concerns regarding warfarin therapy and their association with warfarin adherence and anticoagulation control. Thromb Res. 2014; 133(4):550-554.

11. Contreras Muruaga MD, Vivancos J, Reig G, et al. Satisfaction, quality of life and perception of patients regarding burdens and benefits of vitamin $\mathrm{K}$ antagonists compared with direct oral anticoagulants in patients with nonvalvular atrial fibrillation. J Comp Eff Res. 2017;6(4): 303-312.

12. Coleman CI, Haas S, Turpie AG, et al. Impact of switching from a vitamin $\mathrm{k}$ antagonist to rivaroxaban on satisfaction with anticoagulation therapy: The XANTUS-ACTS Substudy. Clin Cardiol. 2016;39(10):565-569. 
13. Hanon O, Chaussade E, Gueranger P, Gruson E, Bonan S, Gay A. Patient-reported treatment satisfaction with rivaroxaban for stroke prevention in atrial fibrillation. A French observational study, the SAFARI study. PLoS One. 2016;11(12):e0166218.

14. Fareau S, Baumstarck K, Farcet A, Molines C, Auquier P, Retornaz F. Évaluation de la qualité de vie des patients âgés en fibrillation atriale sous anticoagulants au long cours: antivitamine K versus anticoagulants oraux directs. [Quality of life of elderly people on oral anticoagulant for atrial fibrillation: VKA versus direct oral anticoagulants]. Geriatr Psychol Neuropsychiatr Vieil. 2015;13(1):45-54. French.

15. Fumagalli S, Cardini F, Roberts AT, et al. Psychological effects of treatment with new oral anticoagulants in elderly patients with atrial fibrillation: a preliminary report. Aging Clin Exp Res. 2015;27(1):99-102.

16. Coleman CI, Coleman SM, Vanderpoel J, Nelson W, Colby JA, Scholle JM, Kluger J. Patient satisfaction with warfarin- and nonwarfarin-containing thromboprophylaxis regimens for atrial fibrillation. J Investig Med. 2013;61(5):878-881.

17. Suarez Fernandez C, Mostaza JM, Castilla Guerra L, et al. Seguimiento de las recomendaciones del Informe de Posicionamiento Terapéutico sobre el tratamiento con anticoagulantes orales en pacientes ancianos con fibrilación auricular. Estudio ESPARTA [Adherence to recommendations about treatment with oral anticoagulants in elderly patients with atrial fibrillation. The ESPARTA study]. Medicina Clínica. In press 2017. Spanish.

18. Charlson ME, Pompei P, Ales KL, MacKenzie CR. A new method of classifying prognostic comorbidity in longitudinal studies: development and validation. J Chronic Dis. 1987;40(5):373-383.

19. Suárez C, Pose A, Montero-Pérez-Barquero M, et al. Validación del cuestionario de satisfacción ACTS en pacientes con fibrilación auricular tratados con anticoagulantes orales en España. Estudio ALADIN. [Validation of satisfaction questionnaire ACTS in outpatients with atrial fibrillation treated with oral anticoagulants attended in Internal Medicine and Neurology departments in Spain. ALADIN Study]. Med Clin (Barc). 2016;147(5):192-198. Spanish.
20. Cano SJ, Lamping DL, Bamber L, Smith S. The Anti-Clot Treatment Scale (ACTS) in clinical trials: cross-cultural validation in venous thromboembolism patients. Health Qual Life Outcomes. 2012;10:120.

21. Barrios V, Escobar C, Prieto L, et al. Anticoagulation control in patients with nonvalvular atrial fibrillation attended at primary care centers in Spain: The PAULA Study. Rev Esp Cardiol (Engl Ed). 2015;68(9):769-776.

22. Anguita Sánchez M, Bertomeu Martínez V, Cequier Fillat Á; CALIFA study researchers. Quality of vitamin $\mathrm{K}$ antagonist anticoagulation in Spain: prevalence of poor control and associated factors. Rev Esp Cardiol (Engl Ed). 2015;68(9):761-768.

23. Dagres N, Nieuwlaat R, Vardas PE, et al. Gender-related differences in presentation, treatment, and outcome of patients with atrial fibrillation in Europe: a report from the Euro Heart Survey on Atrial Fibrillation. J Am Coll Cardiol. 2007;49(5):572-577.

24. Anguita-Sánchez M, Marco-Vera P, Alonso-Moreno FJ, et al. Percepción de los médicos sobre los factores que influyen en la elección de un dicumarínico o de un nuevo anticoagulante oral en pacientes con fibrilación auricular no valvular. [Perception of physicians on factors that influence the choice of a dicoumarin or a new oral anticoagulant in patients with non-valvular atrial fibrillation]. Aten Primaria. 2016;48(8):527-534. Spanish.

25. Corbi IS, Dantas RA, Pelegrino FM, Carvalho AR. Health related quality of life of patients undergoing oral anticoagulation therapy. Rev Lat Am Enfermagem. 2011;19(4):865-873.

26. Haas S, Ten Cate H, Accetta G, et al. Quality of vitamin K antagonist control and 1-year outcomes in patients with atrial fibrillation: a global perspective from the GARFIELD-AF registry. PLoS One. 2016;11(10): e0164076.
Patient Preference and Adherence

\section{Publish your work in this journal}

Patient Preference and Adherence is an international, peer-reviewed, open access journal that focuses on the growing importance of patient preference and adherence throughout the therapeutic continuum. Patient satisfaction, acceptability, quality of life, compliance, persistence and their role in developing new therapeutic modalities and compounds to optimize

\section{Dovepress}

clinical outcomes for existing disease states are major areas of interest for the journal. This journal has been accepted for indexing on PubMed Central. The manuscript management system is completely online and includes a very quick and fair peer-review system, which is all easy to use. Visit http://www. dovepress.com/testimonials.php to read real quotes from published authors. 